\title{
Measuring Physical Load in Soccer: Strengths and Limitations of 3 Different Methods
}

\author{
Karin Fischer-Sonderegger, Wolfgang Taube, Martin Rumo, and Markus Tschopp
}

\begin{abstract}
Purpose: To investigate the strengths and limitations of different indicators to measure physical load. Furthermore, indicators were evaluated for discrimination between performance levels and playing positions. Methods: Ninety positional match files from 70 elite players and 91 match files from 69 subelite players were collected during 14 official under-18 matches using a local position measurement system. Indicators are calculated from speed, absolute acceleration (acc-abs), or percentage acceleration (acc-\%). The acc-\% describes the level of acceleration depending on the maximal voluntary acceleration $\left(a_{\max }\right)$ for each initial running speed. Effect sizes (ES) were used to determine discriminative ability. Results: The number of high accelerations largely depended on the method (absolute threshold $\left[>3 \mathrm{~m} \cdot \mathrm{s}^{-2}\right.$ and $\left.>4 \mathrm{~m} \cdot \mathrm{s}^{-2}\right] 120$ and 59 efforts; high percentage threshold $\left[>75 \% a_{\mathrm{max}}\right]$ 84 efforts). Only a small number of highly accelerated efforts reached speeds considered high-speed running $\left(>19.8 \mathrm{~km} \cdot \mathrm{h}^{-1}\right.$ : $32.6 \%$ ). More high acc-\% exists from initial running speed $>2 \mathrm{~m} \cdot \mathrm{s}^{-1}(23.0)$ compared with acc-abs $\left(>3 \mathrm{~m} \cdot \mathrm{s}^{-2} 14.4,>4 \mathrm{~m} \cdot \mathrm{s}^{-2} 5.9\right)$. Elite players achieve higher values in most performance indicators, with ES being highest for the number of high acc-\% $(\mathrm{ES}=0.91)$ and high acc-abs $\left(>3 \mathrm{~m} \cdot \mathrm{s}^{-2} \mathrm{ES}=0.86,>4 \mathrm{~m} \cdot \mathrm{s}^{-2} \mathrm{ES}=0.87\right)$, as well as for covered distance in jogging $(E S=0.94)$. Conclusions: Estimated physical load, discriminative ability of physical indicators, and positional requirements largely depend on the applied method. A combination of speed-based and acc-\% methods is recommended to get a comprehensive view.
\end{abstract}

Keywords: intensity, monitoring, motion analysis, local position measurement, physical indicator

The primary purpose for monitoring physical load in soccer is to provide information to practitioners to optimize physical performance and to minimize the risk of injury. ${ }^{1-3}$ To estimate the physical load, different performance indicators are used. Traditional indicators usually encompass the distance a player covered in different speed zones. ${ }^{4}$ However, several studies have pointed out that speed-based indicators do not reveal the complete picture of physical load in soccer. ${ }^{5-11}$ Due to the fact that efforts with high accelerations requires a greater amount of energy and a higher muscular demand than constant-speed efforts ${ }^{10}$; the physical load is underestimated with speed-based methods. Therefore, a growing number of intermittent team sports research integrated acceleration-based indicators taking into account all efforts with accelerations above a given absolute threshold $\left(\mathrm{eg},>3.0 \mathrm{~m} \cdot \mathrm{s}^{-2}\right) .^{5,9,11-14}$ However, this approach does not consider the fact that the maximum possible acceleration progressively decreases with increasing initial running speeds. ${ }^{15}$ Therefore, using absolute acceleration (acc-abs) thresholds underestimate the energetic and muscular loads when efforts start from an already relatively high initial running speed $\left(\mathrm{eg},>14.4 \mathrm{~km} \cdot \mathrm{h}^{-1}\right)$. A recently introduced approach tried to solve this problem. ${ }^{15}$ The percentage acceleration (acc-\%) method classifies the intensity of the effort based on the ratio of the actual measured acceleration of the specific effort and the maximum voluntary acceleration that is possible from this initial running speed. The maximum voluntary acceleration from different initial running speeds can be calculated from an isolated maximal sprint test. Compared with the acc-abs method, which

Fischer-Sonderegger, Rumo, and Tschopp are with the Swiss Federal Inst of Sport Magglingen, Magglingen, Switzerland. Fischer-Sonderegger and Taube are with Movement and Sport Science, Dept of Neurosciences and Movement Sciences, University of Fribourg, Fribourg, Switzerland. Fischer-Sonderegger (karin. fischer@baspo.admin.ch) is corresponding author. used generic (and often arbitrary) values across all players, either individual or team-specific maximal values are used to calculate the acc- $\%$ thresholds. Hence, the acc- $\%$ method offers a more precise estimation of the level of the acceleration and therefore of the physical load. However, so far, this method was only validated in experimental setups but was not tested during real soccer matches. Therefore, the first aim of this study was to show the differences in load estimation when measuring physical load during matches using acc-abs $9,12,13$ and acc-\% methods, ${ }^{15}$ as well as the traditional speed-based approach. ${ }^{16,17}$

The second aim of the study was to evaluate the discriminative ability of different physical indicators derived from speed-based, acc-abs, and acc-\% methods. Because of the complex nature of soccer, measuring the influence of a single performance indicator to the overall match performance is impossible. Instead, the strength of the discrimination ability of performance indicators between players of different performance levels or different playing positions can be indirectly used to determine the relevance of an indicator. ${ }^{18}$ To date, the importance of the different aspects of physical performance for success in soccer has not been clearly revealed yet. ${ }^{19-23}$ Furthermore, acceleration-based methods have not been used - to our knowledge-when comparing players of different performance levels. Therefore, the discriminative ability of different speed- and acceleration-based indicators was determined by comparing under-18 (U18) youth soccer players of 2 different performance levels and different field positions.

\section{Methods}

\section{Participants}

Seventy elite junior players at the highest U18 level (mean [SD]): age, 17.0 (0.6) years; height, $178.1(6.3) \mathrm{cm}$; body mass, 70.9 
(7.6) $\mathrm{kg}$; training volume, and 9.6 (2.0) hours per week and $69 \mathrm{sub}$ elite junior players of the second-highest U18 level: age, $17.9(0.9)$ years; height, $176.4(5.2) \mathrm{cm}$; body mass, 70.1 (6.5) kg; training volume, and 4.5 (1.2) hours per week participated in the study. Ninety match files from elite junior players (20 participants with 2 match files and 50 participants with 1 match file) and 91 match files from sub-elite junior players (22 participants with 2 match files and 47 participants with 1 match file) were collected.

Only match files from players who completed the entire match were included in the study. For comparisons between the playing positions, only match files from elite field players were included. They were analyzed and categorized according to Di Salvo et $\mathrm{al}^{21}$ into the following positions: central defenders $(C D ; n=15,22$ match files), wide defenders (WD; $\mathrm{n}=18,24$ match files), central midfielders (CM; $\mathrm{n}=17,21$ match files), wide midfielders (WM; $\mathrm{n}=7,8$ match files), and attackers (A; $\mathrm{n}=13,15$ match files). The players were free from injury and illness. The study protocol was in accordance with the Declaration of Helsinki and was approved by the institutional review board of the Swiss Federal Institute of Sport Magglingen.

\section{Championship Matches}

- Fourteen official championship matches of the highest $(n=7)$ and second-highest $(n=7)$ national U18 championship level in Switzerland were analyzed using positional data. Fourteen different teams participated in the study. For the purpose of this study, all matches were played on the same pitch on artificial turf with the same measurement system. The weather was dry and windless, with temperatures of approximately $20^{\circ} \mathrm{C}$. Before the matches, players completed a 25-minute warm-up and 4 maximal sprints to evaluate maximal acceleration from different initial running speeds (see below).

\section{Measurement System}

Positional data were measured using a local position measurement (LPM) system (inmotiotec GmbH, Regau, Austria). The LPM system records data with a sampling frequency of $1000 \mathrm{~Hz}$ divided by the number of players. Therefore, the temporal resolution was approximately $45 \mathrm{~Hz}$. The LPM accuracy depends on the type of movement (eg, linear or multidirectional) and on the type of indicator (eg, average or peak values). ${ }^{24}$ The coefficient of variation in mean speed is between $1.4 \%$ and $3.9 \%{ }^{25}$ and the averaged absolute bias for peak speed $0.03(0.72) \mathrm{km} \cdot \mathrm{h}^{-1}$ and for peak acceleration $0.48(1.27) \mathrm{m} \cdot \mathrm{s}^{-2} \cdot 24$

\section{Measurement Methods}

Three different methods were used to estimate physical load.

The speed-based method determined the distance covered in different speed zones. In this study, the following 6 speed zones were used, according to Rampinini et $\mathrm{al}^{16}$ and Bradley et $\mathrm{al}^{17}$ : standing, 0.0 to $0.7 \mathrm{~km} \cdot \mathrm{h}^{-1}$; walking, $>0.7$ to $7.2 \mathrm{~km} \cdot \mathrm{h}^{-1}$; jogging, $>7.2$ to $14.4 \mathrm{~km} \cdot \mathrm{h}^{-1}$; running, $>14.4$ to $19.8 \mathrm{~km} \cdot \mathrm{h}^{-1}$; high-speed running, $>19.8$ to $25.2 \mathrm{~km} \cdot \mathrm{h}^{-1}$; and sprinting, $>25.2 \mathrm{~km} \cdot \mathrm{h}^{-1}$.

The acc-abs method classified the intensity of the effort based on the maximum acc-abs reached. The indicators show the number of efforts with accelerations above a certain absolute threshold. Acceleration thresholds and the terminology of the classifications were chosen according to previous publications ${ }^{11,14}$ : low acceleration $\left(>1-2 \mathrm{~m} \cdot \mathrm{s}^{-2}\right)$, moderate acceleration $\left(>2-3 \mathrm{~m} \cdot \mathrm{s}^{-2}\right)$, and high acceleration $\left(>3 \mathrm{~m} \cdot \mathrm{s}^{-2}\right)\left(\right.$ acc-3). Bradley et $\mathrm{al}^{13}$ described efforts with accelerations $>4 \mathrm{~m} \cdot \mathrm{s}^{-2}$ as efforts with high accelerations (acc-4); therefore, a second threshold for high acceleration was also considered.

The acc-\% method ${ }^{15}$ classified the intensity of an effort based on the ratio of the actual measured acceleration of this specific effort and the maximum voluntary acceleration $\left(a_{\max }\right)$ that was possible from this initial running speed $\left(v_{\text {init }}\right)$. To determine the $v_{\text {init }}$ of an effort in as complex a situation as a soccer match, we implemented the method of Sonderegger et al ${ }^{15}$ and defined $v_{\text {init }}$ as the speed when an effort starts, meaning when the acceleration turns positive. The actual measured acceleration considered the entire locomotor action, and the maximal acceleration value of this specific action ( $\left.a_{\text {max,action }}\right)$ was extracted. By contrast, the $a_{\max }$ was determined in a sprint test conducted prior to the matches. The sprint test includes 4 maximal sprints over $50 \mathrm{~m} .{ }^{15}$ The first sprint was performed from a standing start, whereas subsequent sprints were performed out of 1 of 3 constant initial running speeds (6.0, 10.8 , and $15 \mathrm{~km} \cdot \mathrm{h}^{-1}$ ). Recovery time between each sprint was 3 minutes. Knowing the $v_{\text {init }}$ and the corresponding $a_{\max }$ of the 4 sprints allowed determination of a group-specific regression equation. Thus, $a_{\max }$ can be identified for any $\mathrm{v}_{\text {init }}$ and therefore the percentage of $a_{\max }$ can be calculated for each single effort in soccer matches. The resulting acc-\% indicators show the number of efforts with accelerations higher than a certain percentage threshold. Thresholds were set as follows: very low $\left(<25 \% a_{\max }\right)$, low $\left(\begin{array}{lll}<50 \% & a_{\max }\end{array}\right)$, moderate $\left(<75 \% a_{\max }\right)$, and high $\left(\geq 75 \% a_{\max }\right)$.

Indicators extracted with the acc-abs and the acc-\% methods are further separated, depending on the $v_{\text {init }}$, into efforts initiated from running speeds $0-1,>1-2,>2-3,>3-4$, and $>4 \mathrm{~m} \cdot \mathrm{s}^{-1}$. This approach - based on Varley and Aughey ${ }^{26}$ - shows differences in number of efforts with high accelerations initiated within the different speed bands dependent on the used method.

To categorize efforts according to the level of acceleration, each single efforts must be recognized. The method used to detect the efforts and the filtering technique adopted can strongly influence the number of recognized efforts. ${ }^{27}$ In this study, the highfrequency part of the acceleration signal (=noise) was removed using a Butterworth low-pass filter (order 5) with a frequency cutoff of 0.02. The start of an effort was defined when acceleration turned from negative (deceleration) to positive, and the end of an effort was set when the maximum speed was reached (ie, when the acceleration became 0). Subsequently, further efforts were considered as irrelevant and removed if the maximal speed did not exceed $1.2 \mathrm{~m} \cdot \mathrm{s}^{-1}$ or the total speed increase of the effort $\left(v_{\max }-v_{\text {init }}\right)$ was smaller than $0.9 \mathrm{~m} \cdot \mathrm{s}^{-1}$. These thresholds helped to ensure that only meaningful efforts were integrated into the data analysis (following the advice of Varley et $\mathrm{al}^{27}$ ). Due to large variation of a single-peak acceleration using the LPM system, Stevens et $\mathrm{al}^{24}$ propose to use the number of actions above a certain threshold $\left(\mathrm{eg},>4 \mathrm{~m} \cdot \mathrm{s}^{-2}\right)$ during longer periods of play instead of the exact absolute value of peak acceleration. Thresholds are used in both the acc-abs and the acc-\% methods.

\section{Statistical Analysis}

All data were reported as means (90\% confidence interval). The ability of an indicator to discriminate between elite and sub-elite players was quantified using pooled Cohen's effect sizes (ES) $(90 \%$ confidence interval). ${ }^{28}$ In addition, differences between junior elite and sub-elite players were analyzed using an independent $t$ test. To detect positional differences, elite junior players were separated according to their position. The ability of an indicator to 
discriminate between positions was also quantified using pooled Cohen's ES (90\% confidence interval). ${ }^{28}$ Furthermore, differences between playing positions were analyzed using a 1-way analysis of variance and Tukey's post hoc tests. The absolute ES of $<0.2,<0.6$, $<1.2,<2.0$, and $<4.0$ were used to represent trivial, small, moderate, large, and very large differences, respectively, between elite and sub-elite players. ${ }^{29}$ Statistical significance was set at $P<.05$. Statistical analyses were performed using SPSS (version 22.0 for Windows; SPSS Inc, Chicago, IL).

\section{Results}

\section{Comparison of the 3 Methods}

The total number of high accelerations depended on the selected method (Figure 1). With the acc-\% method (accelerations $\geq 75 \%$ $\left.a_{\max }\right), 83.7(80.1 ; 87.3)$ highly accelerated efforts per player were detected, whereas with acc-3, $119.2(115.1 ; 123.2)$ efforts and with acc-4, $58.7(56.0 ; 61.4)$ efforts per player were recorded. Furthermore, the number of efforts with a high acceleration and initial running speed from 0 to $1 \mathrm{~m} \cdot \mathrm{s}^{-1}$ was more than twice as high with acc-3 $(63.4[61.2 ; 65.6])$ than with acc-4 $(30.7[29.1 ; 32.3])$ or with high acc-\% (29.7 [28.1; 31.2]). Only $35.5 \%(34.3 \% ; 36.6 \%)$ of all efforts with high acc-\% started with running speeds from 0 to $1 \mathrm{~m} \cdot \mathrm{s}^{-1}$, whereas $53.2 \%(52.2 \% ; 54.2 \%)$ and $52.3 \%(51.1 \%$; $53.6 \%)$ of all efforts with acc-3 and acc- 4 started with running speeds from 0 to $1 \mathrm{~m} \cdot \mathrm{s}^{-1}$.

Noticeably more efforts were recognized as high accelerations with initial running speed $>2 \mathrm{~m} \cdot \mathrm{s}^{-1}$ when the acc-\% method was used instead of the acc-abs method. $23.0(21.8 ; 24.3)$ efforts with high acc-\% had initial running speeds $>2 \mathrm{~m} \cdot \mathrm{s}^{-1}(27.5 \%[26.4 \%$; $28.5 \%$ ] of all high acc-\%), whereas only $14.4(13.5 ; 15.4)$ efforts $(12.1 \%[11.5 \% ; 12.7 \%]$ of all acc- 3$)$ and only $5.9(5.5 ; 6.4)$ efforts $(10.1 \%$ [9.5\%; $10.8 \%]$ of all acc-4) were recognized with acc-3 and acc-4, respectively.

For each of the 3 classification methods, the majority of high acceleration efforts did not obtain high running speeds. For high acc-\%, $56.3(53.3 ; 59.3)$ efforts $(67.1 \%$ [65.3\%; 68.8\%] of all high acc-\%) did not reach $19.8 \mathrm{~km} \cdot \mathrm{h}^{-1}$, whereas $90.9(87.1 ; 94.8)$ efforts with acc-3 $(76.1 \%$ [74.6\%; 77.5\%] of all acc-3) and 43.2 $(40.8 ; 45.6)$ efforts with acc-4 $(73.4 \%[71.6 \% ; 75.2 \%]$ of all acc-4) did not obtain the high-speed running threshold.

Furthermore, only $7.0 \%(6.2 \% ; 7.8 \%)$ of all efforts with high acc-\% and only $4.4 \%(3.8 \% ; 4.9 \%)$ and $5.1 \%(4.4 \% ; 5.8 \%)$ of all efforts with acc-3 and acc-4 reached a maximal running speed $>25.2 \mathrm{~km} \cdot \mathrm{h}^{-1}$.

\section{Ability of Indicators to Discriminate Between Performance Levels and Field Positions}

Table 1 shows all indicators of physical load determined either with the speed-based, the acc-abs, or the acc-\% method. The largest differences with moderate ES existed in the number of efforts with high acc-\% $(\mathrm{ES}=0.91[0.64 ; 1.16])$, in the number of efforts with acc-3 $(\mathrm{ES}=0.86[0.60 ; 1.11])$, and in the number of efforts with acc-4 $(\mathrm{ES}=0.87[0.61 ; 1.12])$. Elite players performed more high accelerations than sub-elite players. Even though elite players performed more efforts with moderate accabs and moderate acc-\% than sub-elite players, they only revealed small ES. No differences between elite and sub-elite players and trivial respectively small ES existed in the number of efforts with low acc-abs and low acc-\%.

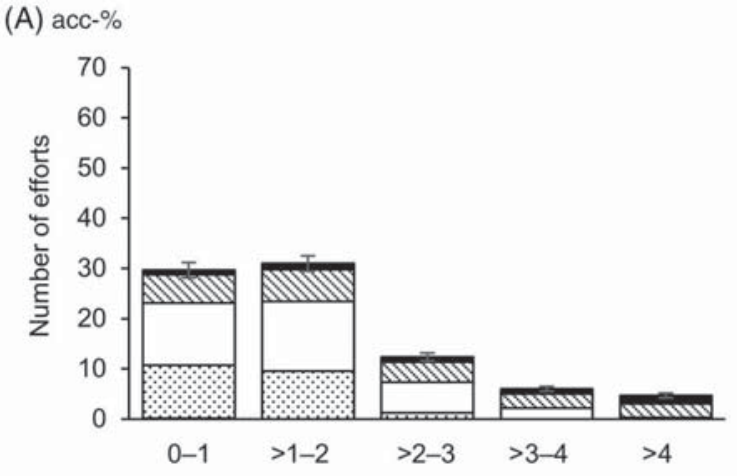

(B) acc-3

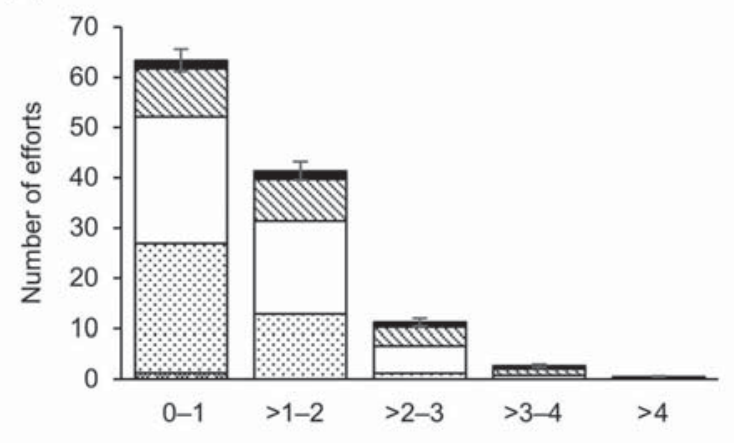

(C) acc-4

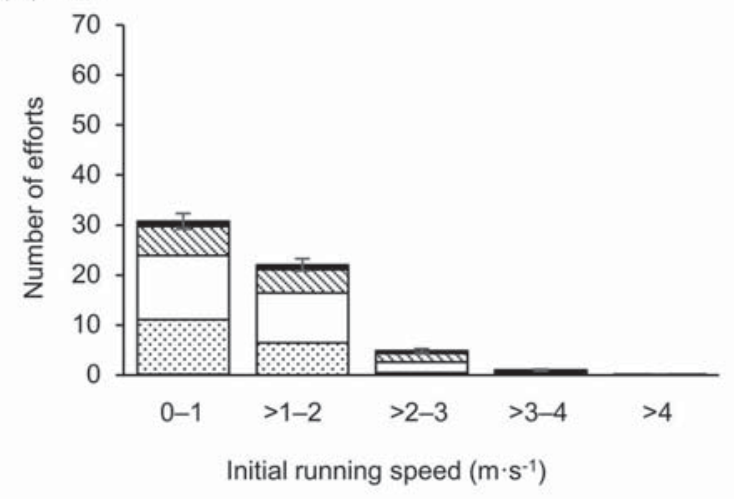

Walking $\left(>0.7-7.2 \mathrm{~km} \cdot \mathrm{h}^{-1}\right) \otimes \mathrm{HSR}\left(>19.8-25.5 \mathrm{~km} \cdot \mathrm{h}^{-1}\right)$
Jogging $\left(>7.2-14.4 \mathrm{~km} \cdot \mathrm{h}^{-1}\right)$ Sprinting $\left(>25.5 \mathrm{~km} \cdot \mathrm{h}^{-1}\right)$
Running $\left(>14.4-19.8 \mathrm{~km} \cdot \mathrm{h}^{-1}\right)$

Figure 1 - All efforts with high accelerations (including 90\% CI) depending on the used method. (A) The number of efforts with accelerations $\geq 75 \% a_{\max }$. (B and C) The number of efforts with accelerations $>3 \mathrm{~m} \cdot \mathrm{s}^{-2}$ and $>4 \mathrm{~m} \cdot \mathrm{s}^{-2}$. The efforts are split up depending on the initial running speed ( $x$-axis) and the maximum running speed (different speed zones). Abbreviations: acc, acceleration; $a_{\max }$, maximal voluntary acceleration; HSR, high-speed running.

The ES of the distances in the running, high-speed running, and sprinting categories were markedly lower $(0.50-0.64)$ than the $\mathrm{ES}$ of the distance in the jogging category $(\mathrm{ES}=0.94[0.67 ; 1.19])$. However, the values for elite players were greater than those observed for sub-elite players. Sub-elite players performed greater distance in the walking category than elite players with moderate $\mathrm{ES}(\mathrm{ES}=-0.83[-1.08 ;-0.57])$. 


\begin{tabular}{|c|c|c|c|c|c|c|c|}
\hline & \multicolumn{7}{|c|}{ Match } \\
\hline & \multicolumn{2}{|c|}{ Elite } & \multicolumn{2}{|c|}{ Subelite } & \multirow[b]{2}{*}{ ES } & \multirow[b]{2}{*}{$\begin{array}{c}90 \% \mathrm{Cl} \\
\text { Lower; Upper }\end{array}$} & \multirow[b]{2}{*}{$P$} \\
\hline & Mean (SD) & $\begin{array}{c}90 \% \mathrm{Cl} \\
\text { Lower; Upper }\end{array}$ & Mean (SD) & $\begin{array}{c}90 \% \mathrm{Cl} \\
\text { Lower; Upper }\end{array}$ & & & \\
\hline \multicolumn{8}{|l|}{ Distance in speed zone, $\mathrm{m}$} \\
\hline Sprinting $\left(>25.2 \mathrm{~km} \cdot \mathrm{h}^{-1}\right)$ & $111(72)$ & $99 ; 124$ & $76(64)$ & $65 ; 87$ & 0.51 & $0.26 ; 0.76$ & .00 \\
\hline High-speed running $\left(>19.8-25.2 \mathrm{~km} \cdot \mathrm{h}^{-1}\right)$ & $522(181)$ & $490 ; 553$ & $432(182)$ & $400 ; 463$ & 0.50 & $0.25 ; 0.74$ & .00 \\
\hline Running $\left(>14.4-19.8 \mathrm{~km} \cdot \mathrm{h}^{-1}\right)$ & $1508(331)$ & $1450 ; 1566$ & $1281(376)$ & $1216 ; 1347$ & 0.64 & $0.38 ; 0.89$ & .00 \\
\hline Jogging $\left(>7.2-14.4 \mathrm{~km} \cdot \mathrm{h}^{-1}\right)$ & $4353(764)$ & $4219 ; 4487$ & $3638(763)$ & $3505 ; 3771$ & 0.94 & $0.67 ; 1.19$ & .00 \\
\hline Walking $\left(>0.7-7.2 \mathrm{~km} \cdot \mathrm{h}^{-1}\right)$ & $3976(305)$ & $3922 ; 4029$ & $4280(418)$ & $4207 ; 4353$ & -0.83 & $-1.08 ;-0.57$ & .00 \\
\hline Standing $\left(0.0-0.7 \mathrm{~km} \cdot \mathrm{h}^{-1}\right)$ & $25(8)$ & $23 ; 26$ & $26(12)$ & $24 ; 28$ & -0.13 & $-0.37 ; 0.12$ & .39 \\
\hline \multicolumn{8}{|l|}{ Number of efforts with absolute acceleration } \\
\hline $\operatorname{High}\left(>4.0 \mathrm{~m} \cdot \mathrm{s}^{-2}\right)$ & $64(16)$ & $61 ; 67$ & $50(15)$ & $48 ; 53$ & 0.87 & $0.61 ; 1.12$ & .00 \\
\hline $\operatorname{High}\left(>3.0 \mathrm{~m} \cdot \mathrm{s}^{-2}\right)$ & $127(23)$ & $123 ; 131$ & $107(25)$ & $102 ; 111$ & 0.86 & $0.6 ; 1.11$ & .00 \\
\hline Moderate $\left(>2.0-3.0 \mathrm{~m} \cdot \mathrm{s}^{-2}\right)$ & $113(16)$ & $110 ; 115$ & $106(17)$ & $103 ; 109$ & 0.37 & $0.13 ; 0.62$ & .01 \\
\hline Low $\left(>1.0-2.0 \mathrm{~m} \cdot \mathrm{s}^{-2}\right)$ & $166(19)$ & $162 ; 169$ & $165(23)$ & $161 ; 169$ & 0.01 & $-0.23 ; 0.25$ & .94 \\
\hline \multicolumn{8}{|l|}{$\begin{array}{l}\text { Number of efforts with percentage } \\
\text { acceleration }\end{array}$} \\
\hline $\operatorname{High}\left(\geq 75 \% a_{\max }\right)$ & $84(21)$ & $81 ; 88$ & $66(20)$ & $63 ; 69$ & 0.91 & $0.64 ; 1.16$ & .00 \\
\hline Moderate $\left(<75 \% a_{\max }\right)$ & $90(14)$ & $87 ; 92$ & $82(18)$ & $79 ; 85$ & 0.48 & $0.23 ; 0.72$ & .00 \\
\hline Low $\left(<50 \% a_{\max }\right)$ & $183(21)$ & $179 ; 187$ & $176(26)$ & $171 ; 181$ & 0.28 & $0.04 ; 0.53$ & .06 \\
\hline Very low $\left(<25 \% a_{\max }\right)$ & $77(16)$ & $74 ; 80$ & $85(20)$ & $81 ; 89$ & -0.43 & $-0.67 ;-0.18$ & .00 \\
\hline
\end{tabular}

Abbreviations: $a_{\max }$, maximal voluntary acceleration; CI, confidence interval; ES, effect size (Cohen $d$ ). Note: Values are for the entire match. Indicators of 3 different methods are compared: (1) the speed-based method with the corresponding indicators-distance covered in different speed zones; (2) the absolute acceleration-based method with the corresponding indicators_number of efforts above a given absolute acceleration threshold, and (3) the percentage acceleration-based method with the corresponding indicators-number of efforts above a given percentage acceleration threshold. A positive ES represents a larger mean for elite players. Statistical significance was set at $P<.05$.

Table 2 shows all indicators of physical load dependent on the playing position, determined either with the speed-based, the acc-abs, or the acc-\% method. CD covered less distance in the running category compared with all other field positions, with large to very large ES; moreover, they covered the least distance in the jogging category, with moderate to large ES (except for A, with trivial ES). In addition, CD had the CD had the fewest number of efforts with high acc-\% with moderate to large ES compared with players in other field positions and also the least number of efforts with acc- 3 and acc- 4 but with small to moderate ES.

The CM had the highest number of efforts with high and moderate acc-\% and the highest number of efforts with acc-3 and acc-4, with moderate to large ES (except for A, with small ES). In addition, the distances covered in the jogging and running categories were the greatest for CM compared with all other field positions, with moderate to very large ES. On the contrary, CM covered less distance in the sprinting category than players in other positions, with moderate to very large ES.

The WD and A covered the greatest distances in the highspeed running and sprinting categories compared with the other field positions, with moderate to very large ES (except for A compared with WM, with small ES). The number of efforts with high acc-\% was similar to that in other field positions (except for A compared with $\mathrm{CD}$, with A had more high acc-\%).

\section{Discussion}

This study shows the strengths and limitations of the frequently used speed-based and the acc-abs methods, as well as the newly published acc-\% method to assess physical load in soccer. Furthermore, this study demonstrates the relevance of acceleration-based physical indicators in discriminating between soccer players of different performance levels and when describing positional requirements.

\section{Strengths and Limitations of the Speed-Based and the 2 Acceleration-Based Methods}

A great number of efforts with high accelerations reach only low or moderate maximal running speeds. For instance, more than twothirds of the highly accelerated efforts resulted in maximal running speeds lower than $19.8 \mathrm{~km} \cdot \mathrm{h}^{-1}$. These results are in accordance with the results from Varley and Aughey. ${ }^{26}$ They showed that $85 \%$ of the maximal accelerations had a final speed $<15.0 \mathrm{~km} \cdot \mathrm{h}^{-1}$. Thus, the nomenclature of the speed-based method may indicate a different activity than was actually performed by the player because often only efforts with running speeds exceeding a certain speed threshold (eg, >19.8 $\mathrm{km} \cdot \mathrm{h}^{-1}$ ) are considered as high-intensity activity. ${ }^{30,31}$ The potential for misinterpretation of physical load based solely on speed-zone data might be critical as not only the motor effort itself (classified as jogging despite being an accelerating sprint) but also the intensity (classified as "low" in jogging vs "high" in accelerating sprints) is misleadingly classified.

The misinterpretation also becomes obvious when positional differences are considered. In particular, CM have the greatest number of efforts with high acc-\% and the greatest distance in the jogging and running category but shorter distance in the high-speed running category and the least distance in the sprinting category. Therefore, if only speed-based indicators are used to estimate 


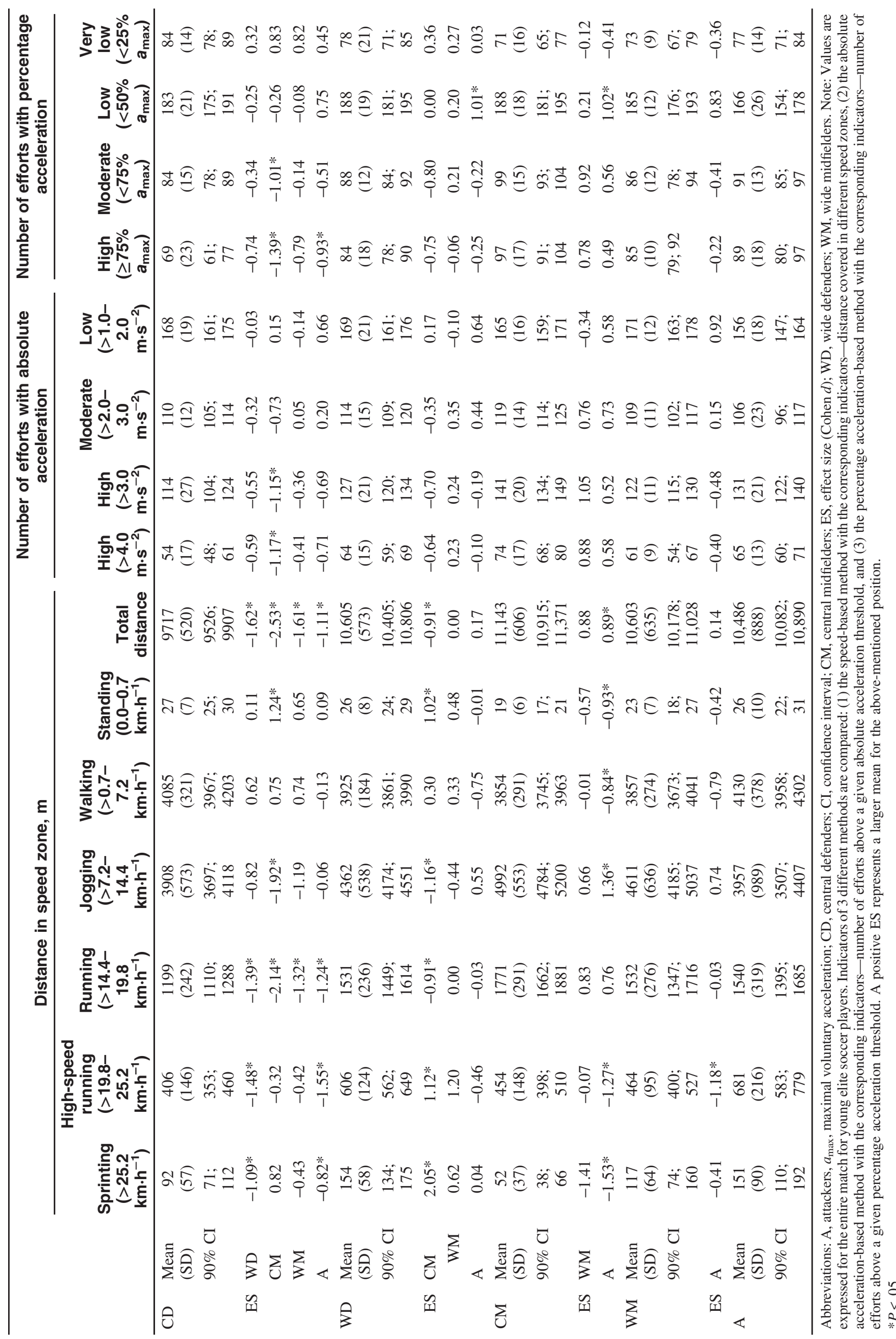


physical load, a relevant contributor to the physical load in soccer is disregarded as stated earlier. ${ }^{5-11}$

By contrast, WD and A covered the greatest distances in the high-speed running and sprinting category compared with the other positions but had a similar number of efforts with high acc- $\%$ (except for $\mathrm{A}$ and $\mathrm{CD}$ ). In this case, if only acceleration-based indicators are used, important aspects of these positions are neglected. Therefore, an evaluation either only taking indicators of the acceleration-based methods or indicators of the speed-based method into account would misinterpret physical load.

More than one-half of all efforts with acc-3 have initial running speeds between 0 and $1 \mathrm{~m} \cdot \mathrm{s}^{-1}$, and only 14.4 efforts $(12.1 \%$ of all acc-3) started from speeds $>2 \mathrm{~m} \cdot \mathrm{s}^{-1}$. These results are very similar to already published results. ${ }^{26}$ By contrast, only a third of all efforts with high acc- $\%$ have initial speeds between 0 and $1 \mathrm{~m} \cdot \mathrm{s}^{-1}$, and almost one-third of all efforts with high acc-\% have initial running speeds $>2 \mathrm{~m} \cdot \mathrm{s}^{-1}$. As soccer players are often already in motion prior to an accelerated effort to anticipate a match situation or to follow an opponent, it seems logical that a relevant number of efforts are initiated from a speed exceeding standing or walking. Because even junior soccer players reach values of $6 \mathrm{~m} \cdot \mathrm{s}^{-2}$ when accelerating maximally from a standing position, ${ }^{15} 3 \mathrm{~m} \cdot \mathrm{s}^{-2}$ may be too low a threshold for categorizing high acceleration for efforts starting with a low initial running speed. Therefore, a threshold of $>3 \mathrm{~m} \cdot \mathrm{s}^{-2}$ for high acceleration misclassifies efforts starting with low initial running speeds as maximum accelerations even if they are only submaximal. As a consequence, twice as many efforts are counted as efforts with high acceleration when the threshold is set at $>3 \mathrm{~m} \cdot \mathrm{s}^{-2}$ than when it is set at $>4 \mathrm{~m} \cdot \mathrm{s}^{-2}$ (120 vs 59 efforts). Furthermore, using a fixed absolute threshold incorrectly classifies maximally accelerated efforts starting with high initial running speeds as submaximal accelerations. This is even more pronounced the higher the absolute threshold is set. Therefore, when an absolute threshold of $>4.0 \mathrm{~m} \cdot \mathrm{s}^{-2}$ was chosen as a high acceleration, only 5.9 efforts $(10.1 \%$ of all acc-4) started from initial running speeds $>2 \mathrm{~m} \cdot \mathrm{s}^{-1}$. The reason for this misclassification was previously highlighted by showing that the acceleration capacity decreases with increasing initial running speed. ${ }^{15}$

The results of our study suggest that the quantification of the physical load and the nomenclature of the term "high acceleration" can also be incorrect when an abs-acc method is used. For example, Varley and Aughey ${ }^{26}$ defined the threshold for maximal accelerations by $>2.78 \mathrm{~m} \cdot \mathrm{s}^{-2}$. As two-third of all "sprints" $\left(\geq 6.94 \mathrm{~m} \cdot \mathrm{s}^{-1}\right)$ have accelerations $\leq 2.78 \mathrm{~m} \cdot \mathrm{s}^{-2}$, they conclude that during matchplay, a player is not always demanded to accelerate maximally to achieve maximal speed. However, this statement may be imprecise, as the level of accelerations from "sprints" initiated at higher running speeds are wrongly classified. For example, efforts initiated from $16.7 \mathrm{~km} \cdot \mathrm{h}^{-1}$ have maximal accelerations ${ }^{15}$ of $2.29 \mathrm{~m} \cdot \mathrm{s}^{-2}$ and would therefore be classified as submaximal. This misinterpretation has consequences not only when practitioners need to quantify the load the players are exposed to but also from the point of view of training methodology. The use of the abs-acc method may neglect the need to also train maximally accelerated runs from a higher initial running speed, which involves different muscle groups and limb movement speeds/step patterns. ${ }^{32}$

The acc- $\%$ method avoids the biases introduced by the abs-acc method. In contrast to the speed-based and the acc-abs methods, it calculates the intensity thresholds either on the basis of individual results or on the basis of a team average. Consequently, a sprint test with maximal accelerations initiated from different running speeds is required to calculate the $25 \%, 50 \%$, and $75 \%$ acceleration thresholds. This approach has the advantage that the thresholds are performance dependent and are not generic (and arbitrary) values as with absolute thresholds. On the other hand, additional time for sprints and for analyzing positional data is needed (see "Measurement Methods"). It has to be noted at this stage that effort have been made to use relative, individualized thresholds for the speed-based method as well. ${ }^{30,33,34}$ However, these approaches also require additional time to determine individual maximum speed or second ventilatory threshold.

\section{Discriminative Ability of Indicators}

The number of efforts with high abs-acc and high acc-\% discriminates the most between elite and sub-elite junior soccer players, underpinning the importance of a good acceleration ability and the willingness to repeatedly accelerate highly during matches at high performance level. When considering speed-based indicators, it seems odd at first glance that the distance covered in the jogging category discriminates the best. However, the reason for this finding is based on the fact that elite players have more high accelerations than sub-elite players, and most of these efforts take place in the speed range between 7.2 and $14.4 \mathrm{~km} \cdot \mathrm{h}^{-1}$. Thus, the great discriminative ability of the distance in the jogging category is reinforced by these short, highly accelerated efforts and is not only the result of a large number of continuous runs. Each acceleration that either finishes, starts, or passes through the jogging zone will contribute to the distance covered in the jogging category, although the effort itself is obviously much more intense. In contrast to our study, some studies with adult participants have shown that players with higher performance levels have the greatest difference to players of lower levels in the distances covered in high-speed zones. ${ }^{19}$ There are also studies showing that lower ranked teams covered more distance in the high-speed running category than higher ranked teams..$^{20-23}$ However, none of these former studies have taken accelerationbased indicators into account.

\section{Strengths and Limitations of the Study}

With the limited number of players, there is a lack of repeated measurement, and therefore, the player variation between matches was unable to be accounted for. However, the design of the study has the strength that all matches were played on the same match location, ${ }^{35}$ using the same measurement system (LPM), the same playing surface ${ }^{36}$ and pitch dimensions, and the matches were played in the same phase of the season ${ }^{37}$ and under the same climatic conditions. ${ }^{38}$ In addition, because many different teams were included $(n=14)$, the influence of team tactics as well as individual player features can be reduced. All these reasons may lead to a reduction of the match-to-match variation. However, the discriminative ability between junior elite and sub-elite players and between different playing positions is limited to the sample used in this study and can only be transferred to other populations with caution.

The sub-elite players were on average 0.9 years older than the elite players (17.9 vs $17.0 \mathrm{y}$ ). It might be speculated that the discriminative ability of the indicators may have been even greater when the 2 groups had exactly the same average age.

Despite being muscularly demanding, deceleration phases were not considered in the acceleration-based methods nor adequately for the speed-based method. This limitation of the methods should be kept in mind as a practitioner when monitoring the physical load of a training process or a match. Further studies are 
needed to analyze the deceleration performance of the players as it is a relevant contributor of the overall physical load.

Furthermore, approaches exist suggesting to use relative and individualized thresholds for the speed-based method too. ${ }^{30,33,34}$ This may further improve the sensitivity of this approach to determine physical load based on speed data.

When using the acc-abs and the acc-\% methods, the technological aspects of any tracking system may represent a considerable limit. The LPM system seems to be one of the most accurate measurement systems to measure movement patterns in team sports $;{ }^{39}$ nevertheless, its limitations are known. ${ }^{40}$

\section{Practical Applications}

- For a complete picture of the physical load in soccer, a combination of the acc-\% and the speed-based method is recommended.

- Adjusting the nomenclature of the speed-based indicators would be preferable to avoid confusion about the type of movements (eg, "low speed" instead of jogging, "very high speed" instead of sprinting).

- Using acc-abs thresholds to describe efforts with high acceleration, the number of detected efforts depends on the level of the threshold.

- In strength and conditioning training, attention must be paid to the development of the ability to maximally accelerate, while starting not only from low initial running speeds but also from moderate and high ones as well.

\section{Conclusions}

Our results show the relevance of the acceleration ability for high performance in soccer, at least in junior elite players, and the importance of acceleration-based data for the evaluation of physical load. As maximal acceleration depends on the initial running speed, the acc-\% method should be favored to acc-abs thresholds. A combination of speed-based and acceleration-based methods is important to get a comprehensive view, as each method on its own misses some important motor efforts. However, further studies are needed to conclusively determine the definitive procedure to record the total physical load.

\section{Acknowledgments}

The authors thank the Swiss Football Association for their supportive collaboration during the study and the players and their soccer clubs for their committed participation. The authors would also like to thank Marie Javet and Remo Fischer (from the Swiss Federal Institute of Sport Magglingen) for their assistance during testing sessions. The authors declare no conflict of interest.

\section{References}

1. Akenhead R, Nassis GP. Training load and player monitoring in highlevel football: current practice and perceptions. Int J Sports Physiol Perform. 2016;11(5):587-593. PubMed ID: 26456711 doi:10.1123/ ijspp.2015-0331

2. Bourdon PC, Cardinale M, Murray A, et al. Monitoring athlete training loads: consensus statement. Int J Sports Physiol Perform. 2017;12(suppl 2):S2161-S2170. PubMed ID: 28463642 doi:10. 1123/IJSPP.2017-0208
3. Malone S, Owen A, Mendes B, Hughes B, Collins K, Gabbett TJ. High-speed running and sprinting as an injury risk factor in soccer: can well-developed physical qualities reduce the risk? J Sci Med Sport. 2018;21(3):257-262. PubMed ID: 28595870 doi:10.1016/j. jsams.2017.05.016

4. Di Salvo V, Baron R, Tschan H, Calderon MFJ, Bachl N, Pigozzi F. Performance characteristics according to playing position in elite soccer. Int J Sports Med. 2007;28(3):222-227. PubMed ID: 17024626 doi:10.1055/s-2006-924294

5. Akenhead R, Harley J, Tweddle S. Examining the external training load of an English premier league football team with special reference to acceleration. J Strength Cond Res. 2016;30(9):2424-2432. PubMed ID: 26817740 doi:10.1519/JSC.0000000000001343

6. di Prampero PE, Botter A, Osgnach C. The energy cost of sprint running and the role of metabolic power in setting top performances. Eur J Appl Physiol. 2015;115(3):451-469. PubMed ID: 25549786 doi:10.1007/s00421-014-3086-4

7. Gaudino P, Iaia FM, Alberti G, Hawkins RD, Strudwick AJ, Gregson W. Systematic bias between running speed and metabolic power data in elite soccer players: influence of drill type. Int J Sports Med. 2014;35(6):489-493. PubMed ID: 24165959 doi:10.1055/s-00331355418

8. Gaudino P, Iaia FM, Alberti G, Strudwick AJ, Atkinson G, Gregson W. Monitoring training in elite soccer players: systematic bias between running speed and metabolic power data. Int J Sports Med. 2013;34(11):963-968. PubMed ID: 23549691 doi:10.1055/s-00331337943

9. Ingebrigtsen J, Dalen T, Hjelde GH, Drust B, Wisloff U. Acceleration and sprint profiles of a professional elite football team in match play. Eur J Sport Sci. 2015;15(2):101-110. PubMed ID: 25005777 doi: 10.1080/17461391.2014.933879

10. Osgnach C, Poser S, Bernardini R, Rinaldo R, di Prampero PE. Energy cost and metabolic power in elite soccer: a new match analysis approach. Med Sci Sports Exerc. 2010;42(1):170-178. PubMed ID: 20010116 doi:10.1249/MSS.0b013e3181ae5cfd

11. Akenhead R, Hayes PR, Thompson KG, French D. Diminutions of acceleration and deceleration output during professional football match play. J Sci Med Sport. 2013;16(6):556-561. PubMed ID: 23333009 doi:10.1016/j.jsams.2012.12.005

12. Aughey RJ. Australian football player work rate: evidence of fatigue and pacing? Int J Sports Physiol Perform. 2010;5(3):394-405. PubMed ID: 20861528 doi:10.1123/ijspp.5.3.394

13. Bradley PS, Di Mascio M, Peart D, Olsen P, Sheldon B. Highintensity activity profiles of elite soccer players at different performance levels. J Strength Cond Res. 2010;24(9):2343-2351. PubMed ID: 19918194 doi:10.1519/JSC.0b013e3181aeb1b3

14. Hodgson C, Akenhead R, Thomas K. Time-motion analysis of acceleration demands of $4 \mathrm{v} 4$ small-sided soccer games played on different pitch sizes. Hum Mov Sci. 2014;33:25-32. PubMed ID: 24576705 doi:10.1016/j.humov.2013.12.002

15. Sonderegger K, Tschopp M, Taube W. The challenge of evaluating the intensity of short actions in soccer: a new methodological approach using percentage acceleration. PLoS One. 2016;11(11):e0166534. PubMed ID: 27846308 doi:10.1371/journal.pone.0166534

16. Rampinini E, Coutts AJ, Castagna C, Sassi R, Impellizzeri FM. Variation in top level soccer match performance. Int J Sports Med. 2007;28(12):1018-1024. PubMed ID: 17497575 doi:10.1055/s2007-965158

17. Bradley PS, Sheldon W, Wooster B, Olsen P, Boanas P, Krustrup P. High-intensity running in English FA Premier League soccer matches. J Sports Sci. 2009;27(2):159-168. PubMed ID: 19153866 doi:10.1080/02640410802512775 
18. Impellizzeri FM, Marcora SM. Test validation in sport physiology: lessons learned from clinimetrics. Int J Sports Physiol Perform. 2009; 4(2):269-277. PubMed ID: 19567929 doi:10.1123/ijspp.4.2.269

19. Mohr M, Krustrup P, Andersson H, Kirkendal D, Bangsbo J. Match activities of elite women soccer players at different performance levels. J Strength Cond Res. 2008;22(2):341-349. PubMed ID: 18550946 doi:10.1519/JSC.0b013e318165fef6

20. Bradley PS, Carling C, Gomez Diaz A, et al. Match performance and physical capacity of players in the top three competitive standards of English professional soccer. Hum Mov Sci. 2013;32(4):808-821. PubMed ID: 23978417 doi:10.1016/j.humov.2013.06.002

21. Di Salvo V, Gregson W, Atkinson G, Tordoff P, Drust B. Analysis of high intensity activity in Premier League soccer. Int J Sports Med. 2009;30(3):205-212. PubMed ID: 19214939 doi:10.1055/s-00281105950

22. Di Salvo V, Pigozzi F, Gonzalez-Haro C, Laughlin MS, De Witt JK. Match performance comparison in top English soccer leagues. Int J Sports Med. 2013;34(6):526-532. PubMed ID: 23184481 doi:10. 1055/s-0032-1327660

23. Rampinini E, Impellizzeri FM, Castagna C, Coutts AJ, Wisloff U. Technical performance during soccer matches of the Italian serie a league: effect of fatigue and competitive level. J Sci Med Sport. 2009; 12(1):227-233. PubMed ID: 18083631 doi:10.1016/j.jsams.2007. 10.002

24. Stevens TGA, de Ruiter CJ, van Niel C, van de Rhee R, Beek PJ, Savelsbergh GJP. Measuring acceleration and deceleration in soccerspecific movements using a local position measurement (LPM) system. Int J Sports Physiol Perform. 2014;9(3):446-456. PubMed ID: 24509777 doi:10.1123/ijspp.2013-0340

25. Frencken W, Lemmink K, Delleman N. Soccer-specific accuracy and validity of the local position measurement (LPM) system. J Sci Med Sport. 2010;13(6):641-645. PubMed ID: 20594910 doi:10.1016/j. jsams.2010.04.003

26. Varley MC, Aughey RJ. Acceleration profiles in elite Australian soccer. Int J Sports Med. 2013;34(1):34-39. PubMed ID: 22895869 doi:10.1055/s-0032-1316315

27. Varley MC, Jaspers A, Helsen WF, Malone JJ. Methodological considerations when quantifying high-intensity efforts in team sport using global positioning system technology. Int J Sports Physiol Perform. 2017;12(8):1059-1068. PubMed ID: 28051343 doi:10. 1123/ijspp.2016-0534

28. Cohen J. Statistical Power Analysis for the Behavioural Sciences. Hillsdale, MI: Lawrence Erlbaum; 1988.

29. Batterham AM, Hopkins WG. Making meaningful inferences about magnitudes. Int J Sports Physiol Perform. 2006;1(1):50-57. PubMed ID: 19114737 doi:10.1123/ijspp.1.1.50
30. Abt G, Lovell R. The use of individualized speed and intensity thresholds for determining the distance run at high-intensity in professional soccer. J Sports Sci. 2009;27(9):893-898. PubMed ID: 19629838 doi:10.1080/02640410902998239

31. Fessi MS, Zarrouk N, Di Salvo V, Filetti C, Barker AR, Moalla W. Effects of tapering on physical match activities in professional soccer players. J Sports Sci. 2016;34(24):2189-2194. PubMed ID: 27065344 doi:10.1080/02640414.2016.1171891

32. Schache AG, Dorn TW, Williams GP, Brown NA, Pandy MG. Lower-limb muscular strategies for increasing running speed. J Orthop Sports Phys Ther. 2014;44(10):813-824. PubMed ID: 25103134 doi:10.2519/jospt.2014.5433

33. Gabbett TJ. Use of relative speed zones increases the high-speed running performed in team sport match play. J Strength Cond Res. 2015;29(12):3353-3359. PubMed ID: 26020710 doi:10.1519/JSC. 0000000000001016

34. Murray NB, Gabbett TJ, Townshend AD. The use of relative speed zones in Australian football: are we really measuring what we think we are? Int J Sports Physiol Perform. 2018;13(4):442-451. PubMed ID: 28872423 doi:10.1123/ijspp.2017-0148

35. Lago C. The influence of match location, quality of opposition, and match status on possession strategies in professional association football. J Sports Sci. 2009;27(13):1463-1469. PubMed ID: 19757296 doi:10.1080/02640410903131681

36. Andersson H, Ekblom B, Krustrup P. Elite football on artificial turf versus natural grass: movement patterns, technical standards, and player impressions. J Sports Sci. 2008;26(2):113-122. PubMed ID: 17852688 doi:10.1080/02640410701422076

37. Kempton T, Sullivan C, Bilsborough JC, Cordy J, Coutts AJ. Match-to-match variation in physical activity and technical skill measures in professional Australian Football. J Sci Med Sport. 2015;18(1):109-113. PubMed ID: 24444753 doi:10.1016/j.jsams. 2013.12.006

38. Mohr M, Nybo L, Grantham J, Racinais S. Physiological responses and physical performance during football in the heat. PLoS One. 2012;7(6):e39202. PubMed ID: 22723963 doi:10.1371/journal.pone. 0039202

39. Hoppe MW, Baumgart C, Polglaze T, Freiwald J. Validity and reliability of GPS and LPS for measuring distances covered and sprint mechanical properties in team sports. PLoS One. 2018; 13(2):e0192708. PubMed ID: 29420620 doi:10.1371/journal.pone. 0192708

40. Ogris G, Leser R, Horsak B, Kornfeind P, Heller M, Baca A. Accuracy of the LPM tracking system considering dynamic position changes. J Sports Sci. 2012;30(14):1503-1511. PubMed ID: 22906154 doi:10.1080/02640414.2012.712712 